\title{
Liberais, católicos e a educação da mulher: Afrânio Peixoto e Madre Peeters (Brasil, 1930-1950)
}

\section{Liberals, Catholics and education of women: Afrânio Peixoto and Madre Peeters (Brazil, 1930-1950)}

\section{Liberales, católicos y la educación de la mujer: Afrânio Peixoto y Madre Peeters (Brasil, 1930-1950)}

\author{
Bruna Aparecida Rodrigues Duarte ${ }^{1}$ \\ Décio Gatti Júnior ${ }^{1}$
}

DOI: http://dx.doi.org/10.20435/serie-estudos.v0i0.1275

\begin{abstract}
Resumo: Trata-se da comunicação de resultados de investigação na área de História da Educação, cujo foco está relacionado ao exame da educação da mulher nas concepções liberal e católica, tendo como fonte privilegiada dois importantes livros em circulação no Brasil, desde a década de 1930, a saber: "Noções de Sociologia", de Madre Peeters (1935), e a "A Educação da Mulher", de Afrânio Peixoto (1936), nomeado "Eunice ou a Educação da Mulher" nas edições posteriores. Para tanto, houve cotejamento da bibliografia de referência com o conteúdo disposto nas duas obras mencionadas. Depreende-se do material analisado o reconhecimento dos antagonismos existentes na forma de liberais e de católicos tomarem o processo de formação da mulher e de seu papel na sociedade.
\end{abstract}

Palavras-chave: educação; Igreja; mulher.

Abstract: This paper presents the results of investigation in the area of History of Education, with a focus on examination of education of women in the liberal and Catholic conceptions. Privileged sources of this investigation are two important books in circulation in Brazil from the 1930s, namely, "Noções de Sociologia" ("Concepts of Sociology"), by Madre Peeters (1935), and "A Educação da Mulher" ("Education of Women"), by Afrânio Peixoto (1936), entitled "Eunice ou a Educação da Mulher" ("Eunice or Education of Women") in later editions. To undertake this study, the reference bibliography was compared with the content laid out in the two works mentioned. The material analyzed leads to recognition of the antagonisms in the way of liberals and the way of Catholics of taking up the process of education of women and understanding their role in society.

Keywords: education; Church; women.

Resumen: Se trata de una comunicación de resultados de investigación en el área de la Historia de la Educación, cuyo foco está relacionado con el examen de la educación de la mujer en las

1 Universidade Federal de Uberlândia (UFU), Uberlândia, Minas Gerais, Brasil. 
concepciones liberal y católica, teniendo como fuente privilegiada dos importantes libros en circulación en Brasil, desde la década de 1930, a saber: "Nociones de Sociología", de Madre Peeters (1935), y “La Educación de la Mujer", de Afrânio Peixoto (1936), nombrado "Eunice o la Educación de la Mujer" en las ediciones posteriores. Para ello, existió un cotejamiento de la bibliografía de referencia con el contenido dispuesto en las dos obras mencionadas. Se desprende del material analizado el reconocimiento de los antagonismos existentes en las formas que liberales y católicos asumen el proceso de formación de la mujer y de su papel en la sociedad.

Palabras clave: educación; Iglesia; mujer.

\section{INTRODUÇÃO}

Desde a década de 1870, início do movimento republicano no Brasil, uma concepção nova da vida em sociedade proliferou, ganhando maior proeminência com a Proclamação da República, em 1889, em um embate de ideias e de concepções de mundo que transitaram ao longo da primeira metade do Século XX. Sem dúvida, o republicanismo brasileiro era influenciado pelo positivismo comtiano, com a carga de civismo e de cientificismo que ele comportava. A natureza do embate estava atrelada à posição da Igreja Católica, uma verdadeira reação ao que existia de moderno na ideia de República, com o claro objetivo de manter a relevância do catolicismo na sociedade e no Estado brasileiro.

Segundo consta em Peixoto (1947, p. 28), durante a Idade Média, a mulher havia sido definida como "a porta por onde o diabo entra ao homem" e a "lança mais forte do demônio", de modo a ser considerada perigosa, tornando o ato de educá-la inaceitável, pois seria o mesmo que dar armas ao inimigo. Ideias como esta ecoavam no corpo social, dado que o catolicismo influenciava o imaginário social, o que incluía o governo, sendo que tais pensamentos eram fortalecidos com a criação de raízes profundas, fortalecendo uma representação da mulher como incompleta e incapaz.

Distante de tais ideias, Peixoto, que era entusiasta das ideias liberais e cientificistas em sua época, publicou em 1936 a obra "A Educação da Mulher", na qual tomou a mulher como alguém "para ser companheira, a colaboradora, a inspiradora, com iguais direitos e deveres" (1947, p. 11), o que denotava uma alteração fundamental advinda do campo liberal e moderno, em oposição às mencionadas concepções católicas tradicionais.

Estes ideários concorrentes em torno do papel da mulher na sociedade fomentavam um embate que era bastante visível em diferentes publicações, livros, 
revistas e mesmo em manuais disciplinares, uma vez que eles tinham grande penetração no meio social, sobretudo com o advento da escola obrigatória, aberta a todos, e a estruturação de instituições dedicadas à formação de professores.

Nesta direção, este artigo aborda a visão de liberais e de católicos sobre a educação da mulher no Brasil, na primeira metade do Século XX, tendo como fonte privilegiada a obra "Noções de Sociologia", de Madre Peeters, com primeira edição em 1935, publicada pela Companhia Melhoramentos de São Paulo, e a obra "A Educação da Mulher", de Afrânio Peixoto, com primeira edição datada de 1936, publicada pela Companhia Editora Nacional, sendo nomeada, em edições posteriores, "Eunice ou a Educação da Mulher".

Para melhor compreender o cenário e o embate travado pelos liberais e católicos em relação à educação da mulher, a investigação comportou o levantamento, a seleção, a leitura e análise de bibliografia de referência relacionada ao tema da educação da mulher na primeira metade do Século XX, bem como o exame de trabalhos que tenham tido como objeto as obras privilegiadas na presente análise.

A apresentação dos resultados está dividida em três partes inter-relacionadas. Na primeira, aborda-se o contexto histórico do embate entre ideias liberais e católicas no Brasil. Na segunda, verifica-se a visão sobre a educação da mulher presente na obra de Afrânio Peixoto. Na terceira e última parte, observa-se a forma como a educação da mulher foi tomada na obra redigida pela Madre Peeters. Nas considerações finais, destaca-se a análise dos elementos antagônicos nas duas diferentes visões de educação da mulher.

\section{CONTEXTO HISTÓRICO DO EMBATE ENTRE LIBERAIS E CATÓLICOS NO BRASIL}

A Igreja Católica, segundo Araújo (1986), influenciou a cultura brasileira, pois possuía "enorme poder de resistir e adaptar-se às mudanças da sociedade" (p. 11) e tinha como fundamento de seus pensamentos duas eclesiologias que caminhavam juntas, a cristandade e a sociedade perfeita; o princípio básico da cristandade era a integração da Igreja ao Estado, sendo o catolicismo a religião oficial, o que possibilitaria a união dos poderes, com a formação de uma civilização cristã, conforme conteúdo de Casta Pastoral de 1890 (apud ARAÚJO, 1986, p. 86): 
Queremos, sim, a união; mas a união que resulta do acordo e da harmonia, que é única compatível com o sagrado dos interesses confiados à nossa guarda, com o decoro e a honra do nosso sacerdócio, com a própria dignidade e os verdadeiros interesses do outro poder.

No caminho dessa união, porém, embates foram travados por católicos e liberais, uma vez que, neste último campo, existiam correntes que almejavam uma sociedade sem interferência religiosa, com predomínio do Estado, o que repercutiu em perdas de precedências educacionais e de recursos financeiros pela Igreja.

Nessa direção, a Carta Pastoral de 1900 continha a afirmativa de que, ao romper a relação com a Igreja, o povo teria rompido com Cristo, tendo como resultado muitos problemas na Pátria, já que a primeira constituição sem citação religiosa foi escrita em 1891, inclusive, formalizando a apostasia (abandono da fé, religião), a saber:

Não é de admirar, amados filhos, que tantos males se hajam desencadeado sobre nossa pátria. Quiseram nossos chefes que ela se constituísse de todo independente de Nosso Senhor Jesus Cristo, protestaram nada querer, nenhuma relação ter com Jesus, nem com sua Igreja; e Jesus Cristo, que, queiram ou não queiram os homens, é, e há de ser eternamente o Rei de todo criado, Jesus a quem seu Pai entregou o domínio do universo como herança e em prêmio da morte afrontosa por ele sofrida, nos vai mostrando o que vale um país sem Deus. Coroou a Constituição Brasileira todos os passados erros declarando-se apóstata formal e independente de toda idéia e sentimento religioso, e oficialmente temos feito timbre de desprezar o nome de Deus, que nem uma vez ainda se proferiu nos documentos públicos. E Deus, a quem nem as constituições, nem os exércitos podem depor de seu trono, retirou-nos um pouco sua mão beneficente, deixou-nos entregues à nossa própria miséria, feitos ludíbrio de todos os males: lição eloqüente para que os outros povos se escarmentem em nós, e vejam aonde vai parar um povo que rejeitou a seu Deus. (Carta Pastoral de 1900 apud ARAÚjO, 1986, p. 54-5).

A Igreja defendia a ideia de que a existência do Brasil só teria sido possível pelas mãos de Deus (ARAÚJO, 1986, p. 66), sendo que a vinda dela para o Brasil "amansou e civilizou os primitivos habitantes do nosso país" (ARAÚJO, 1986, p. 69). Assim, além de ter sido essencial no início da construção da nação, ela teria sido o único meio de formar verdadeiros patriotas, pois a "formação do crente 
significa a formação do patriota; pessoas bem integradas no espírito religioso estarão prontas ao apelo da pátria. E o clero brasileiro tem sido exemplo de amor pátrio" (ARAÚJO, 1986, p. 73). Os católicos argumentavam ainda quão estáveis e prósperas eram províncias e nações que andavam unidas com a Igreja, tais como Buenos Aires, Córdoba, Santa Fé, República do Chile etc.

Embora existissem desavenças entre os grupos católicos, havia algo comum, a certeza de que o mundo estava em crise e, enquanto os católicos afirmavam que era um castigo de Deus ou um retrato do que seria a vida sem Ele, os reformadores sociais acreditavam que "as novas políticas, as novas formas de vida em sociedade, a guerra mundial, o progresso das ciências biológicas e psicológicas e o avanço científico-tecnológico determinavam uma nova mentalidade educacional" (CURY, 1984, p. 69), ou seja, a educação e os seus ideais poderiam se alterar de acordo com a estrutura da sociedade.

Contemplava-se, desse modo, a ideia de que a tecnologia associada ao científico tiraria o homem da crise, dando corpo, desse modo, ao humanismo tecno-científico, que tinha suas bases no homem-sujeito (o homem que se sente fazendo o progresso), na ciência (apresentando a mudança e transformação constante para uma nova mentalidade, pois os auxílios técnicos são eficazes), na evolução e na democracia. Nessa direção, os pioneiros da educação nova não relacionavam à criança com Deus e com o pecado original, preferindo, ao invés disso, adotar uma linguagem científica e sociológica. "Neste sentido o homem é mais descrito do que definido. E assim, o homem só existe enquanto é um ser social" (CURY, 1984, p. 76). Cury afirma que, para os reformadores:

A educação é vista como sendo o veículo integrador das gerações às novas condições de um mundo em mudança. Ela deve organizar-se como instrumento de adaptação às situações novas de um meio social essencialmente dinâmico. Neste sentido a educação é tão imprescindível que do seu sucesso ou não, depende o crescimento ou perecimento da civilização. Por isso ela revê seus meios e fins, para reciclá-los às novas circunstâncias. (CURY, 1984, p. 80).

O embate educacional dava-se, desse modo, entre os religiosos que defendiam a preponderância da Igreja sobre o povo brasileiro, em suas ações e projetos pedagógicos, e os liberais que defendiam a centralidade do Estado, exigindo obrigatoriedade, laicidade, liberdade e gratuidade da instrução. 
Obviamente que essa posição do campo liberal causava reação do campo católico, o qual acreditava que apenas a Igreja proporcionaria uma educação autêntica, para o que divulgavam suas ideias por diversos meios, o que incluía manuais para formação de professores, com a finalidade de conseguir atingir a mentalidade do povo brasileiro.

Interessante mencionar que, neste período inicial da República no Brasil, o catolicismo buscou estabelecer-se novamente como religião oficial do Estado, apostando na imprensa católica e nos investimentos em educação, o que se estendeu até a Revolução de 1930, quando o Governo Vargas passaria a ter a Igreja Católica como importante aliada, conforme ressaltou Oliveira:

Assim, se deu a relação entre a Igreja e Estado: por um lado, ela voltou a se utilizar das estruturas e recursos do Estado, como instituição que trabaIha no campo social, e por outro, o Estado passou a prever fundos para a manutenção de suas estruturas, como as escolas católicas e a inclusão do ensino religioso de frequência facultativa e ministrada conforme os princípios da confissão religiosa do aluno, manifestada pelos pais ou responsáveis. (OLIVEIRA, 2017, p. 85).

\section{AFRÂNIO PEIXOTO E A EDUCAÇÃO DA MULHER}

As transformações pelas quais passou a sociedade brasileira no Século XX são notáveis, sobretudo no período que se estende das décadas de 1930 a 1950, quando economia, política e sociedade se movimentam com velocidade pouco vista antes no Brasil.

Nessa direção, também o papel da mulher brasileira se tornou foco de disputas em relação aos grupos liberal e católico, que buscavam obter e manter sua relevância em um Brasil que se transformava e no qual aspectos da modernidade europeia e norte-americana se faziam presentes.

No campo liberal, foram perceptíveis os esforços de conferir uma nova dimensão ao papel da mulher na sociedade, para além da exclusividade da família, que fosse relacionado ao exercício profissional, visto em sua função emancipadora. A fim de criar o ambiente favorável para que essas mudanças ocorressem, foram disseminadas narrativas que evidenciavam os caminhos percorridos pela mulher na História para que ela atingisse este momento novo e alvissareiro, tal como poderemos examinar na obra de Peixoto (1936). 
Afrânio Peixoto inicia sua obra "A Educação da Mulher", publicada originalmente em 1936, nomeada "Eunice ou a Educação da Mulher" nas edições posteriores, por meio da apresentação da visão dos primitivos em relação à mulher, citando vários povos, começando pelos índios que a viam como dona da casa, da economia doméstica ou tribal, sendo propriedade privada de seu marido, que poderia ter várias esposas, mas com a primeira delas sendo a mais importante, tendo o poder sobre a vida doméstica, porém a preferida seria aquela que tivesse o maior número de filhos.

Figuras 1 e 2 - Capas das edições de 1936 e de 1947 da obra de Afrânio Peixoto
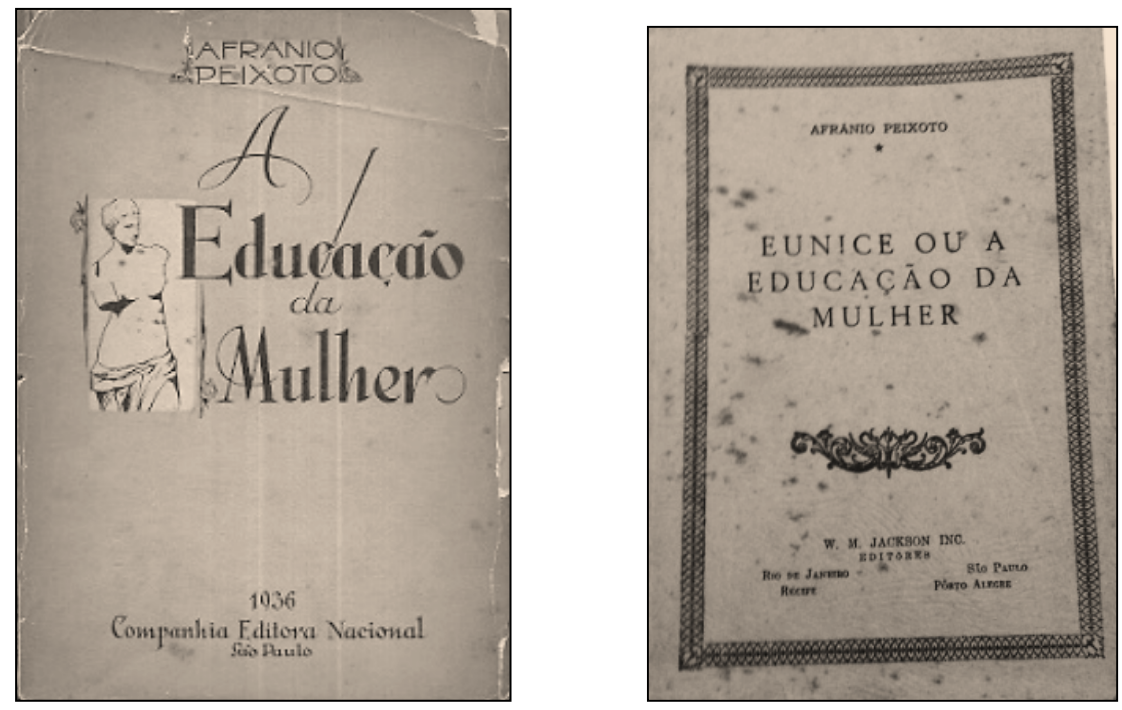

Fonte: Biblioteca da Faculdade de Filosofia, Letras e Ciências Humanas da Universidade de São Paulo.

A criação da prole era de responsabilidade da mulher, até que os meninos pudessem acompanhar os homens para imitá-los na caça, pesca e guerra, enquanto as meninas continuavam cuidando da vida doméstica. A educação era muito simples, ensinavam a higienização íntima e os cuidados, tais como pentear-se, cuidar da casa, cozinhar, conservar a carne dos animais caçados e preparar objetos rudimentares de cerâmica, como potes, panelas, pratos e gamelas. Além da função de cuidar da roça, para levar para a comunidade mandioca, cará, banana 
e outros, em caso de luta com outros povos, serviam de proteção aos homens, sendo utilizadas como barreiras (PEIXOTO, 1947, p. 12).

Na Índia, os hindus não aceitavam o fato de as mulheres saberem ler, seguindo o ditado popular "desconfie da mula que faz him e da mulher que sabe latim" (PEIXOTO, 1947, p. 14). As mulheres na China eram recolhidas, pouco se viam na rua e, quando nasciam, eram recebidas com tristeza, com alto índice de infanticídio. Os árabes exigiam que as mulheres estivessem cobertas, submissas aos homens, que poderiam ter até quatro esposas e inúmeras concubinas.

Com o decorrer do tempo, a visão do que seria a mulher foi se modificando, embora se mantivesse a ideia de submissão e de desvalorização. O surgimento do cristianismo na Idade Média trouxe como herança greco-romana o casamento monogâmico e a mulher como companheira do esposo, e não apenas uma fêmea. O primeiro passo para a educação se tornar acessível às mulheres acabaria por ser motivado por uma necessidade masculina, pois elas seriam "dinas companheiras de seus maridos" (PEIXOTO, 1947, p. 114), sendo mais úteis ao terem o que conversar e sendo mais atraentes para seus esposos, o que tornava importante que elas conhecessem o alfabeto.

Um ponto interessante é o idealismo amoroso, pois a mulher era instruída quanto à leitura, cálculos e comportamento; iniciava-se um momento de exaltação. Esse amor foi definido por Peixoto (1947, p. 41) como cavalheiresco, que "era o amor, idealizado, tão puro, portanto, que não dava logar ao zêlo" (PEIXOTO, 1947, p. 41). A mulher, deste modo, após ser instruída, poderia ser inspiradora, inteligente e culta, ou seja, "a mulher para servi-lo teve de educar-se e se instruir. É daí que vem a mulher moderna: a larva se fêz borboleta” (PEIXOTO, 1947, p. 44).

Durante o Renascimento, as mulheres eram tratadas de modo mais digno, o que teria sido fruto da colaboração de personagens importantes, tais como Erasmo (1467-1536), que, em suas obras, retratava como era a educação, o ensino universitário, definindo a escola onde estudou como "lugar de cuidados e tormentos"; acreditava em uma escola alegre, sem castigos: "nós aprendemos, de boa vontade, tudo, daqueles que amamos" (PEIXOTO, 1947, p. 49). Erasmo era favorável à educação das mulheres, sem desigualdade de sexo, o que era escandaloso naquele período, confrontando-se com os religiosos que defendiam para as mulheres apenas a educação moral, pois, se obtivessem uma educação completa, elas poderiam desviar a si a aos homens do bom caminho. 
João Luís Vivés (1492-1540) era defensor da boa educação para bem educar, ressaltava a importância de conhecer o seu aluno, para assim usar da melhor forma para a construção do conhecimento. Defendia a educação das mulheres, pois acreditava ser absurda a ideia de que a educação as corromperia, o que, segundo ele, só aconteceria às mulheres más, as quais também seriam corrompidas sem educação. Montaigne (1533-1592), por sua vez, acreditava que os homens preferiam estar com mulheres sem educação completamente, pois assim as teriam como dependentes.

De modo geral, nesse período, para as meninas da nobreza e da burguesia terem acesso à educação, o recurso era o convento, onde aprenderiam a ler, mas com enfoque na educação religiosa, em como cuidar da sua família e serviços domésticos. Quando entravam no convento, suas visitas eram cada vez menos frequentes, podendo sair dali apenas com contrato de casamento acertado pela família. Em 1689, em oposição aos conventos, foi publicada uma carta com um pedido de Mme. Sévigné (1626-1696), que vivenciou a realidade dos conventos.

Guarde sua filha consigo; não creia que um convento possa consertar uma educação, nem sôbre assunto de religião, de que nossas monjas não sabem nada, nem sobre outras coisas. Far-lhe-á ler bons livros, conversará com ela: estou persuadida que isto será melhor do que um convento. (MME. SÉVIGNÉ apud, PEIXOTO, 1947, p. 56).

Em relação à educação das meninas, Fénelon (1651-1715) defendia que elas deveriam ser bem educadas, pois "bem que fazem as mulheres bem educadas, e no mal que causam ao mundo quando não tem uma educação que the inspire a virtude" (FÉNELON apud PEIXOTO, 1947, p. 79), ou seja, a má educação das mulheres refletia em coisas ruins que eventualmente aconteciam com os homens, pois as desordens deles podiam acontecer devido à má educação que recebiam da mãe ou das paixões que outras mulheres Ihes inspiraram.

Devido à necessidade dos homens de terem mulheres que soubessem educar e ser boas esposas, para ajudar na prosperidade do esposo, era importante que elas aprendessem a ler e escrever corretamente as quatro regras de aritmética. Recomendava-se até o direito usual, principais regras de justiça, a música, a pintura, a poesia, atentando sempre à condição, ao contexto que essa menina estaria inserida, se seria necessário que tivesse essa educação. 
No período de Revolução, o Marquês de Condorcet (1743-1794) fez constar a ideia de educação da mulher na Constituinte, dado que para ele a instrução dos cidadãos era um imperativo de uma constituição livre, de modo a evitar um povo ignorante e corrompido. Seu programa educacional era dividido em cinco graus de instrução: escolas primárias; escolas secundárias/primárias superiores/complementares; instituto de instrução, de humanidades ou ensino secundário; liceus ou faculdades de ensino superior; sociedade de ciências e de artes/academia/ faculdade de ciência, com a inclusão das mulheres, pois Condorcet acreditava que deveria ser dada a mesma instrução para elas, sem distinção, mas, com o mesmo intuito, para que educassem os filhos e pudessem ser dignas companheiras de seus maridos.

No Século XIX, era corrente a discussão sobre seleção sexual, o que, conforme o evolucionismo social, operaria na distinção dos sexos "considerando a variação maior dos machos nas espécies zoológicas, enquanto as fêmeas conservam maior semelhança com os adolescentes da espécie" (PEIXOTO, 1947, p. 173). Além disso, a escolha dos machos mais atrativos e fortes para suas núpcias, com a escolha de fêmeas mais vistosas, podendo ser disputadas até mesmo por meio da luta. De acordo com determinismo sexual de então, aos homens era atribuída maior importância, por eles movimentarem a economia, serem mais robustos, inteligentes, enquanto a mulher, por sua vez, deveria ser poupada.

Peixoto (1947, p. 184-98) aborda a questão das diferenças, tratando das alterações anatômicas, iniciando-se pelo peso médio de uma criança do sexo masculino, que é de 3.250 gramas, com 50 centímetros de comprimento, e de outra do sexo feminino, de 3.000 gramas, com 49 centímetros de altura, como também sobre o tórax e a bacia.

No homem, o tórax tem forma conoide, mais achatado de diante para trás e mais largo relativamente para cima; nas mulheres, é ovoide, o esterno mais curto e menos oblíquo. A bacia, mais larga, mais ampla e menos alta na mulher do que no homem, com diferenças, milimétricas, de diâmetros, bem como nos cabelos, com presença de gordura e outros detalhes.

A cabeça feminina foi considerada menor, mais delicada, distinguindo-se da masculina, com peso médio do crânio, capacidade e diâmetros menores na mulher. Schopenhauer definia que "a mulher é um animal de cabelos compridos e juízo curto", o que, segundo Peixoto (1947, p. 199), contém dois erros, o 
primeiro deles porque os cabelos já não são mais compridos e o segundo que o juízo nunca foi curto.

No que se refere aos tipos psicológicos, de acordo com Heyman (apud PEIXOTO, 1947, p. 215), há "entre as funções superiores da mulher e as do homem uma diferença de ponto de vista nas sínteses, inexplicável pela educação e pelo hábito". Cohn, por seu turno, afirma que existem traços femininos e masculinos que podem ser percebidos na infância, o que não significa superioridade e inferioridade, somente distinção (PEIXOTO, 1947, p. 216-30). Finalizamos com uma citação importante de Mme. Juliete Adam, na obra de Peixoto sobre a educação das mulheres, com forte conotação moralizante:

É preciso dar às mulheres uma educação séria, e uma educação profissional. É necessário que elas produzam: só o trabalho emancipou o homem; o trabalho apenas será capaz de emancipar a mulher. Que a mulher possa honestamente adquirir as roupas que a veste, a enfeitam, e marchará livre e altiva, na modéstia de uma toilette que revelará sua beleza, sem manchar sua virtude, sem tarifar sua honra. A educação que se dá às mulheres, sendo própria apenas para fazer bonecas, aos olhos dos homens, faz com que as infelizes tomem a sério o papel estúpido que lhe ensinaram, desde a infância. O trabalho é moralizador. (MME. JULIETE ADAM apud PEIXOTO, 1947, p. 243).

\section{A VISÃO DA MULHER NAS “NOÇÕES DE SOCIOLOGIA" DE MADRE PEETERS}

Em contraponto ao caráter emancipador do trabalho e da vida pública profissional presentes no novo papel atribuído às mulheres na Modernidade e, por consequência, no discurso científico, sociológico e liberal do Século XX, surgiu uma oposição consistente, proveniente do campo religioso, que evidenciava, de um lado, a busca da manutenção da relevância da Igreja Católica na sociedade brasileira e, de outro, o esforço de frear a disseminação de ideias consideradas perigosas do campo republicano.

O combate no campo das ideias foi intenso, com vistas à manutenção do poder da Igreja ao lado de um Estado que não sucumbisse ao ideário da Modernidade. Também, aqui, o papel da mulher na sociedade seria ressaltado, todavia, em um registro oposto ao do campo liberal, no qual o lar, não a fábrica, 
e a vida privada, não a vida pública profissional, seriam o ideal formativo da muIher. É exatamente nesta perspectiva que a obra a seguir pode ser enquadrada.

Em "Noções de Sociologia", redigida por Madre Peeters, em 1935, ela afirma que a sociedade, na visão dos modernos, iluministas e positivistas, seria algo natural, pois o homem não conseguiria ficar sozinho, dado que a natureza dele leva à interação, pois a formação da sociedade não depende de sua decisão, mas sim da natureza, de modo a almejar o bem comum, que é

[...] um estado de equilíbrio social, de riquezas intellectuaes, materiaes, de instituições e de legislação tal que cada cidadão, seja qual for sua condição, possa verdadeiramente, comtanto que não se furte às suas obrigações, reivindicar e assegurar o pleno exercício dos seus direitos de homem. (PEETERS, 1935, p. 8-9).

Deste modo, na visão de Madre Peeters, não seria possível o funcionamento da sociedade se não houvesse autoridade para impedir que ela se desagregasse.

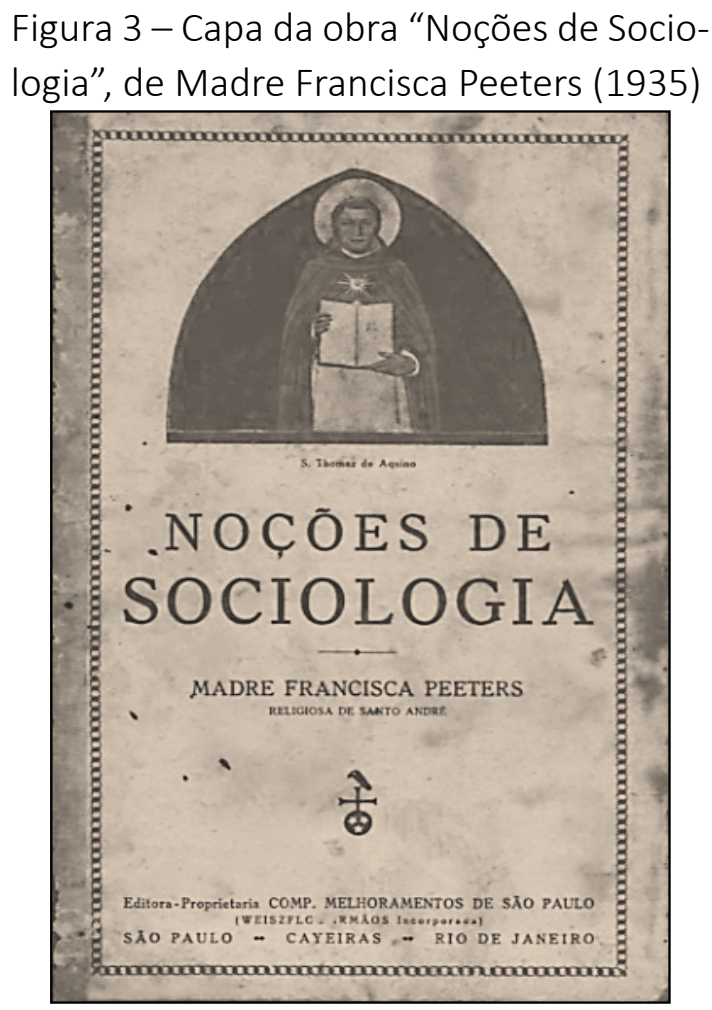

Fonte: Faculdade de Direito da Universidade de São Paulo. 
Dessa forma, para a autora, a teoria de interdependência gera uma consciência coletiva, o que é defendido por Durkheim, uma vez que a decisão de realizar algo não é baseada no individual, mas sim no coletivo, no bem comum. A diferença entre sociedade e Lei social é algo extremamente importante para perceber o embate entre Madre Peeters e as ideias de Durkheim, entre outros, pois a sociedade é decifrável apenas pela ciência que ousa descobrir as condições da vida coletiva, deduzindo daí as leis existentes, enquanto a Lei social procura estudar meios que conduzirão a sociedade implementando direitos e deveres, regulamentando as relações.

Aborda-se, deste modo, a ideia de Lei moral, dado que, para Durkheim, as ações feitas pela maioria do grupo social em que está inserido são consideradas normais e, por consequência, morais, o que é negado por Madre Peeters (1935, p. 16), uma vez que, para ela, o fato de a maioria estar fazendo não condiz com o certo, ou seja, com o moral, utilizando os seguintes exemplos: o uso de entorpecentes é alto em algumas populações, mas não é moral apenas porque a maioria faz o uso, enquanto a consagração da sua alma a Deus é rara, mas não imoral.

Madre Peeters (1935, p. 16-7) afirma que, para manter a vida pura e honesta, o homem precisa muitas vezes ir contra a influência da sociedade, pois a moral é individual, e não consciência coletiva, no que se opõe a Durkheim. A moral cristã age na terra para que no fim tenha posse eterna de Deus.

Marca-se, deste modo, uma distância significativa de Madre Peeters em relação a Durkheim, pois, para ele, "Toda e qualquer doutrina moral, philosophica, religiosa, cujas conclusões, por mais certas e essenciaes que pareçam, só podem viciar um estudo scientifico [...]" (PEETERS, 1935, p. 16).

Madre Peeters travava embate referente ao divórcio com os evolucionistas, que acreditavam que o próximo passo para a família seria o ser livre, ou seja, a abertura para o divórcio, o que era totalmente inaceitável ao catolicismo. Madre Peeters, por seu turno, abordava a origem familiar como algo simples, apoiando-se na Bíblia, na qual se podia ler "Por causa disso, o homem deixará seu pai e sua mãe e ligar-se-á a sua mulher e tornar-se-ão dois numa mesma carne" (Mateus 19:3) e que toda essa "confusão" criada foi resolvida com a vinda de Jesus Cristo encarnado em homem para salvação de todos.

Para Madre Peeters, o matrimônio "é um contrato bilateral pelo qual um homem e uma mulher se dão um ao outro para fundar uma família" (PEETERS, 
1935, p. 26); em verdade, o matrimônio seria uma "instituição" que deveria permanecer independentemente da felicidade dos indivíduos envolvidos, sendo único e sem multiplicidade, ou seja, opondo-se à poligamia e ao divórcio.

Todavia a França foi o primeiro país a introduzir o divórcio (1792), tendo sido anulado em 1816, com retorno em 1884, sendo que houve expansão dessa novidade por todo o mundo, aumentando consideravelmente o número de divórcios, o que ia contra o modo de vida e a doutrina cristã, que toma o matrimônio como um sacramento.

O divorcio destroe para sempre a familia; o desquite afrouxa-Ihe temporariamente os vinculos. Ora, a possibilidade de reconciliação depois de desavenças conjugaes, originadas não raro de impulsidade mal domada, não é uma chimera. (PEETERS, 1935, p. 30).

No que se refere aos filhos, os deveres dos pais são a educação e a instrução nas atividades que eles não conseguem realizar sozinhos. Para ter uma boa formação, e não serem malcriados, os pais precisariam intervir com autoridade, impedindo que o capricho e a inconstância sejam presentes no lugar da disciplina e da educação.

A família, deste modo, desempenha papel social intransferível, uma vez que ela é a célula social, e não o indivíduo; e, como no organismo, todas as células precisam estar em bom estado para sua saúde, assim, as células sociais precisam estar em bom funcionamento para que a sociedade não adoeça, cuidando dos filhos o máximo de tempo possível no lar, evitando internatos até a idade intermediária, quando a carreira profissional deverá ser escolhida.

Até lá, o cristianismo é a única doutrina que deve ser utilizada, pois, se pais soubessem instruir os filhos no caminho de Cristo, eles não se perderiam quando andassem sozinhos.

No que se refere ao cenário familiar, Madre Peeters apresenta a mulher como eterna devedora do cristianismo, com referência à influência que este teve com sua "liberdade" em relação à natureza, como o modo de tratamento do homem e da mulher, utilizando versículo de Paulo, "ordena ao homem que ame a sua mulher como Cristo ama a sua Igreja", assim a mulher era necessária.

A ideia do feminismo defendido pela autora é o que ela nomeia "feminismo moderado", no qual se solicitam direitos que facilitem o funcionamento da família; por exemplo, com o recebimento de uma boa educação, a mulher 
pode acompanhar e orientar os estudos dos filhos, como também ter um emprego e utilizar seu dinheiro como bem entender, desde que a família seja beneficiada.

Porém o feminismo integral é considerado "condenável", pois a ideia de igualdade absoluta entre os sexos e o fim da subordinação da mulher ao marido, segundo a autora: "Arruinaria, se vingasse, a família e faria voltar a sociedade ás horas mais sombrias do paganismo" (PEETERS, 1935, p. 39).

O feminismo, seja o moderado, seja o integral, está relacionado à questão profissional, pois a mulher teria vontade de ir ao mercado de trabalho, mas o que é ensinado a elas por Madre Peeters são os limites impostos, tais como para uma mulher casada, para a qual o melhor trabalho, com maior utilidade e que evitaria prejuízos morais na criação dos filhos, é o lar, pois a saída dessa mulher casada do lar "é sempre uma calamidade" (PEETERS, 1935, p. 40).

A mãe precisa estar em casa para cuidar dos filhos e do esposo, orientando sua educação, e a "ausência forçada da mãe é um elemento de despovoação, ou ao menos causa prejuizo á educação dos filhos" (PEETERS, 1935, p. 40). Já a mulher que não quiser construir uma família poderia buscar trabalho segundo as suas "aptidões naturaes: confecção, obras sociaes, educativas, hospitaleiras, etc." (PEETERS, 1935, p. 41), não indo contra sua essência, buscando não se masculinizar, pois: "Querer transformar esta situação é querer violentar a natureza. As qualidades se perderão, sem que se adquiram as virtudes do outro sexo" (PEETERS, 1935, p. 41).

\section{CONSIDERAÇÕES FINAIS}

A investigação realizada possibilitou compreender melhor o contexto histórico do final do Século XIX e da primeira metade do Século XX, no qual se travou um embate entre liberais e católicos em relação ao poder, à sociedade, à educação em geral e da mulher em particular.

De um lado, os liberais defendiam a ideia de que a sociedade precisaria ser laica para que os desejos dos indivíduos fossem respeitados e a harmonia pudesse triunfar. De outro, os católicos defendiam fervorosamente a necessidade de a Igreja Católica constituir-se como poder junto ao Estado e de se responsabilizar pela formação moral e educacional da nação. 
Estivemos diante de duas visões de mundo, duas estratégias de poder, visíveis nos livros examinados, de Afrânio Peixoto e de Madre Peeters, que denotam a busca de relevância de dois grupos que se opunham no contexto histórico-educacional das primeiras décadas republicanas no Brasil.

De um lado, a ênfase na constituição de uma sociedade laica, livre do predomínio de representações religiosas, em busca da concretude das necessárias mudanças sociais, econômicas e culturais, que abrangiam mudanças de toda ordem, o que incluía a alteração na vida das mulheres, alçadas à possibilidade do exercício profissional, para além das atribuições usualmente autorizadas.

Por outro lado, a Igreja Católica, em busca do resgate da relevância ameaçada pelo crescimento do liberalismo, atuando na direção de frear uma série de mudanças que a afastavam da população e do exercício do poder, com consequências visíveis para a manutenção de uma visão limitada daquilo que poderia ser alterado na vida e na educação das mulheres.

A visão de Madre Peeters em relação à família e à mulher comportava a ideia de sagrado, do zelo eterno, condenando arduamente o divórcio, contra os argumentos dos evolucionistas, que enfatizavam o ser livre e a retirada da mulher como submissa ao esposo. Para Madre Peeters, a mulher só poderia trabalhar em profissões que mantivessem seu papel de cuidadora do lar ou de educadora dos filhos. Portanto as obrigações familiares e da vida privada deveriam ter exclusividade em relação às possibilidades de uma vida pública profissional que se colocava.

É interessante observar, por fim, a forma como o Estado Novo, centralista e autoritário, procedeu uma aliança estratégica entre os interesses estatais e da Igreja Católica, afastando-se da inconveniência das exigências mais radicais do campo liberal, condenando suas lideranças ao ostracismo e fazendo crescer o poder de intelectuais vinculados aos interesses católicos na gestão do campo educacional e cultural governamental, retardando o avanço de uma visão mais liberal do papel da mulher na sociedade brasileira.

Por fim, cabe trazer ideias importantes de Prost (2006, p. 61-113), para quem o processo de evolução social, com a emergência da vida pública profissional, na qual escola e fábrica são fenômenos externos, colaborou para a desinstitucionalização da família, que passaria a ser um lugar de encontro de vidas privadas cada 
vez mais individuais, com a emergência de novos grupos de pertencimento para as novas gerações, externas à família, marcadamente vinculadas ao campo profissional, público por natureza, no qual as mulheres encontraram lugar e, portanto, passaram a questionar o antiquado lar como lugar de confinamento, solicitando mudanças no papel a elas atribuídas na sociedade, mas também aos homens, o que ocorreu, em especial, na décadas de 1960 e 1970, quando a concepção passou a ser opção, e não destino inexorável para as mulheres. Firmou-se uma nova posição social da mulher e surgiram novos dilemas entre o campo liberal e o campo religioso, o que parece ainda encontrar forte presença entre as questões contemporâneas, em especial, no Brasil.

\section{REFERÊNCIAS}

ARAÚJO, José Carlos Souza. Igreja Católica no Brasil: um estudo da mentalidade ideológica. São Paulo: Paulinas, 1986.

CURY, Carlos Roberto Jamil. Ideologia e educação brasileira: católicos e liberais (19301935). 2. ed. São Paulo: Cortez; Autores Associados, 1984.

OLIVEIRA, Sandra Maria. A presença católica na formação de professores no Brasil: os manuais das Madres Peeters e Cooman (1935-1971). 2017. Orientador: Décio Gatti Junior. Tese (Doutorado em Educação) - Universidade Federal de Uberlândia, Uberlândia, MG, 2017.

PEETERS, Madre Francisca. Noções de Sociologia. São Paulo: Companhia Melhoramentos de São Paulo, 1935.

PEIXOTO, Júlio Afrânio. Eunice ou A Educação da Mulher. 2 ed. Rio de Janeiro: W. M. Jackson Inc. Editores, 1947.

PROST, Antoine. A família e o indivíduo. In: PROST, Antoine; VINCENT, Gérard. História da vida privada, 5: da Primeira Guerra a nossos dias. 9. reimp. São Paulo: Companhia das Letras. 2006. p. 61-113. 


\section{Sobre os autores:}

Bruna Aparecida Rodrigues Duarte: Graduada em Enfermagem pela Faculdade de Medicina da Universidade Federal de Uberlândia. Bolsista de Iniciação Científica do CNPq. E-mail: brunaap150@hotmail.com, Orcid: http://orcid.org/0000-0003-0487-455X

Décio Gatti Júnior: Doutor em Educação pela Pontifícia Universidade Católica de São Paulo, com estágio de pós-doutorado concluído na Faculdade de Educação da Universidade de São Paulo. Professor titular de História da Educação na Universidade Federal de Uberlândia. Bolsista de Produtividade em Pesquisa do CNPq. Beneficiário do Programa Pesquisador Mineiro da Fapemig e do Edital Universal do CNPq. E-mail: degatti@ufu.br, Orcid: http://orcid.org/0000-0002-5876-6733

Recebido em 25 de abril de 2019.

Aprovado em 26 de novembro de 2019. 